\title{
IRRIGAÇÃO DE DOIS CULTIVARES DE FEIJÃO (PHASEOLUS VULGARIS L.) COM EFLUENTES DE WETLANDS CONSTRUÍDOS
}

\section{IRRIGATION OF TWO BEAN CULTIVARS (PHASEOLUS VULGARIS L.) WITH EFFLUENTS FROM CONSTRUCTED WETLANDS}

Selma Cristina da Silva.

Doutora em Tecnologia Ambiental e Recursos Hídricos/UnB UFRB. (scsilva00@yahoo.com.br)

Daniele Caldas de Miranda.

Engenheira Sanitarista - CETEC/UFRB. (nielemiranda@gmail.com)

Maria Lucrecia Gerosa Ramos.

PhD em Ecofisiologia Vegetal/Universityof Dundee-UK. UNB. (lucrecia@unb.br )

Submissão: 20 de Maio de 2019

Aceite: 17 de Outubro de 2019

\section{Resumo}

O objetivo do trabalho foi avaliar o efeito dos efluentes produzidos pelos wetlands construídos com meio suporte de solo natural (Latossolo Amarelo), plantados com arroz irrigado (Oryza sativa L.) no suprimento nutricional de dois cultivares de feijão (BRS Estilo e BRS Horizonte), sem adubação química. Os sistemas experimentais de tratamento foram operados em escala reduzida, com diferentes taxas de aplicação hidráulica e seus efluentes armazenados em um tanque para reúso na irrigação do feijão. Antes da aplicação, realizou-se a análise do efluente quanto ao teor de metais, e observou-se que sua qualidade era compatível com aquela recomendada por diferentes autores para a água de reúso na irrigação. Por outro lado, as concentrações de $\mathrm{Ca}^{+2}$ e $\mathrm{Mg}^{+2}$ no efluente eram maiores, e as de $\mathrm{K}^{+}, \mathrm{Mn}$ e $\mathrm{Zn}$, menores do que as requeridas pelo feijão, mesmo assim, as plantas se desenvolveram bem e produziram grãos. $\mathrm{A}$ água de reúso se mostrou adequada para irrigação e suprimento de nutrientes para as plantas. Os cultivares BRS Estilo irrigados com água de reúso alcançaram alturas superiores, aos irrigados com água de poço, cujo solo recebeu adubação tradicional (controle). Entretanto, para o cultivar BRS Horizonte ocorreu o inverso.

Palavras-chave: reúso, solo, esgoto doméstico, cultivo do feijão.

\section{Abstract}

The objective of this work was to evaluate the effect of effluents produced by wetlands built with natural soil support (Yellow Latosol), planted with irrigated rice (Oryza sativa L.) for nutritional supply of two bean cultivars (BRS Estilo and BRS Horizonte), without chemical fertilization. The effluents produced by reduced scale constructed wetland systems, operated at different rates of hydraulic application, were stored in a tank for reuse for common bean irrigation. Prior to application, metal content in the effluent was analyzed. The effluent (treated sewage) was found to be of quality for using in crop irrigation, as metal concentrations were within the limits recommended by different authors for reuse water in irrigation. On the other hand, the concentrations of $\mathrm{Ca}^{+2}$ and $\mathrm{Mg}^{+2}$ in the effluent were higher and those of $\mathrm{K}^{+}, \mathrm{Mn}$ and $\mathrm{Zn}$ lower than those required by common bean, even though the plants developed well and produced grains. Cultivar BRS Estilo irrigated with reused water reached higher heights compared to irrigated with well water, whose soil received traditional fertilization. However, for BRS Horizonte the opposite occurred.

keywords: reuse, soil, domestic sewage, bean cultivation.

\section{INTRODUÇÃO}

O reúso de esgotos tratados na agricultura tem sido um dos mais utilizados (ALMEIDA, 2010), pelo fato do esgoto possuir nutrientes necessários ao crescimento e desenvolvimento das plantas, cujos elementos minerais essenciais são: nitrogênio, fósforo, potássio, cálcio, magnésio, enxofre, boro, cloro, ferro, manganésio, zinco, cobre, molibidênio e níquel. Além disso, tem como elementos benéficos a sílica, o sódio, o cobalto e o selênio, que 
promovem o crescimento de várias plantas, mas não são absolutamente necessários para completar seu ciclo de vida (RODRIGUES, 2008).

Se os esgotos forem aplicados no solo sem o devido controle, as concentrações das espécies solúveis e trocáveis de $\mathrm{Zn}$ aumentam (SALOMONS et al., 1995), porém, em condições anóxicas, podem causar sua precipitação, tornando-o indisponível para a planta. Além disso, outros problemas podem ocorrer como a bioacumulação de elementos tóxicos, a contaminação microbiológica, a salinização, a impermeabilização e o desbalanceamento dos nutrientes no solo (MOSCOSO; LEÓN, 1996). Assim, a irrigação das plantas com os esgotos tratados (água de reúso) pode aumentar as concentrações de sódio e de metais pesados no solo. O aumento dos teores de sódio nos solos altera as suas características físicas, devido à dispersão de argilas que reduz a sua porosidade, a condutividade hidráulica, a taxa de infiltração e, também, causa a destruição da estrutura do solo, bem como as químicas, influenciando, direta ou indiretamente, no desenvolvimento das plantas (FEIGIN; RAVINA; SHALHEVET, 1991). Assim, é necessário realizar o tratamento dos esgotos antes da sua aplicação como água de irrigação, de forma a manter a qualidade do solo e suprir as necessidades hídricas e nutricionais das plantas.

Entre os diversos processos de tratamento de esgoto, têm-se os wetlands construídos. Tratase de uma técnica natural que utiliza meio suporte, planta e microorganismos para a despoluição das águas. No tratamento de águas residuárias, os wetlands são projetados com a finalidade de tratar o esgoto bruto ou previamente tratado (von SPERLING, SEZERINO, 2018). São sistemas controlados que simulam e aceleram as condições naturais encontradas nos terrenos alagados naturais. Os wetlands construídos têm capacidade para remoção de elevadas concentrações de carbono, nitrogênio, fósforo e de metais pesados, devido aos vários processos que ocorrem no interior do reator, tais como: adsorção, filtração, assimilação microbiana, nitrificação, desnitrificação e absorção (RAN; AGAMI; ORON, 2004).

Os meios suportes comumente utilizados nos wetlands construídos são areia grossa, cascalho, pedregulho e brita. Porém, eles se tornam mais atrativos e autossustentáveis quando são utilizados materiais reutilizáveis ou facilmente encontrados na própria comunidade. O solo tem sido pouco utilizado como meio suporte para tratamento de esgotos. O uso do Latossolo Vermelho-amarelo se mostrou eficiente na remoção de matéria orgânica (de 97\% a 99\%,) (SILVA; BERNARDES; RAMOS, 2015) e pouco eficientes tanto na remoção de metais alcalinos e alcalinos terrosos, variando de $11 \%$ a $35 \%$ (SILVA; RAMOS; BERNARDES, 2018), como de metais de transição e pós-transição (SILVA et al., 2012). Assim, ao se utilizar wetlands construídos para tratamento de esgotos domésticos, visando ao reúso de seus efluentes na agricultura, é importante observar se as concentrações dos metais nos efluentes produzidos encontram-se dentro dos limites permissíveis para a água de irrigação e para a cultura, pois o equilíbrio dos metais no solo é fundamental para a manutenção das funções de uma agricultura sustentável (SALOMONS et al., 1995). Logo, os metais devem estar disponíveis no solo em concentrações máximas aceitáveis, para que não o contaminem e inviabilizem o desenvolvimento das culturas.

Assim, o objetivo do trabalho foi avaliar se os efluentes produzidos pelos wetlands construídos com meio suporte de solo natural (Latossolo Amarelo), plantados com arroz irrigado (Oryza sativa L.), poderiam ser utilizados para suprimento das demandas hídricas e nutricionais de duas cultivares de feijão (Phaseolus vulgaris L.) das espécies BRS Estilo e BRS Horizonte, sem que houvesse a necessidade da adubação química.

\section{METODOLOGIA}

Foram concebidos dois sistemas wetlands construídos em escala reduzida, cada um com nove repetições. As unidades experimentais foram representadas por caixas d'águas plásticas com capacidade de 100 litros, altura de 0,41m, diâmetro interno de $0,73 \mathrm{~m}$ e com área superficial de $0,42 \mathrm{~m}^{2}$. Estes foram operados, simultaneamente, com taxas de aplicação hidráulica constante diária de $2,4 \mathrm{~cm} / \mathrm{d}$ e $4,7 \mathrm{~cm} / \mathrm{d}$, respectivamente, com alimentação intermitente alternada, por fluxo vertical em meio não saturado. A intermitência teve como objetivo a aeração do solo, tanto para evitar a sua colmatação como para a nitrificação do efluente a ser reutilizado na irrigação do feijão.

O solo utilizado como meio suporte (camada filtrante) foi o Latos solo Amarelo misturado com areia grossa na proporção de 1,75:1,00 (areia grossa: solo), o que resultou em uma 
condutividade hidráulica de $10^{-2} \mathrm{~cm} / \mathrm{s}$. Este solo era caracterizado como arenoso, uma vez que possuía $86,35 \%$ de areia, 7,65 de silte e $7 \%$ de argila. A camada filtrante tinha altura de $20 \mathrm{~cm}$, a de drenagem de $10 \mathrm{~cm}$ e a folga de $10 \mathrm{~cm}$ para aplicação do esgoto a ser tratado. A tubulação de drenagem era de PVC com diâmetro de $40 \mathrm{~mm}$ totalmente perfurada com orifícios de $1 \mathrm{~cm}$, espaçados a $2,5 \mathrm{~cm}$, envolvidas com bidim e, sobre ela, foi colocada uma camada de $10 \mathrm{~cm}$ de brita $n^{\circ} \mathbf{1}$. Os efluentes dos dois sistemas foram direcionados para uma caixa d'água com capacidade de 1000L, na qual ficaram armazenados para posterior irrigação da cultura do feijão. A qualidade da água de irrigação (efluente tratado) foi analisada com base nos seguintes parâmetros: cobre $(\mathrm{Cu})$, manganês $(\mathrm{Mn})$, níquel $(\mathrm{Ni})$, chumbo $(\mathrm{Pb})$, cobalto $(\mathrm{Co})$, zinco $(\mathrm{Zn})$, cálcio $(\mathrm{Ca})$, magnésio $(\mathrm{Mg})$, sódio $(\mathrm{Na})$, potássio $(\mathrm{K})$ e $\mathrm{pH}$.

O sistema de reúso possuía 12 (doze) unidades experimentais, em escala reduzida, representada por vasos plásticos, sendo 6 (seis) unidades plantadas com a cultivar de feijão BRS Estilo e 6 (seis) com a cultivar BRS Horizonte. Em cada sistema, 3 (três) unidades foram preenchidas com solos não adubados, que receberam o efluente tratado como água de irrigação, e 3 (três), com solos previamente adubados cuja irrigação foi realizada com água de poço (controles).

A coleta, preservação e análises das amostras seguiram os procedimentos do manual "Standard Methods for Examination of Waterand Wastewater" (APHA-AWWA-WPCF, 1985).

O sistema de reúso teve um delineamento experimental de blocos ao acaso com três repetições, em esquema fatorial $2 \times 2$, com 2 (dois) tratamentos (Cultivares de feijão: Estilo $\mathrm{e}$ Horizonte) e 2 (duas) irrigações (Irrigado com efluente e irrigado com água de poço - controle). A análise dos solos seguiu os procedimentos descritos por EMBRAPA (2009) e as análises nutricionais das plantas do feijão foram realizadas seguindo a metodologia de MALAVOLTA et al. (1997).

\section{RESULTADOS E DISCUSSÃO}

As unidades experimentais wetland construídos produziram efluentes com concentrações de metais (Tabela 1) compatíveis com aqueles recomendados para a irrigação de culturas (Tabela 2), seja com água de rio ou água de reúso (esgoto tratado). Contudo, as concentrações de $\mathrm{Ca}^{+2}$ e $\mathrm{Mg}^{+2}$ encontravam-se acima e as de $\mathrm{K}^{+}, \mathrm{Mn}, \mathrm{Zn}$, e $\mathrm{Cu}$, abaixo dos limites recomendados para a cultura do feijão (Tabela 4); mas, isso não interferiu no desempenho e estado nutricional das plantas e dos grãos, uma vez que os resultados obtidos foram semelhantes nos dois sistemas, no adubado tradicionalmente e irrigado com água de poço (controle) e naquele sem adubação irrigado com água de reúso (esgoto tratado).

Os efluentes produzidos pelas unidades wetlands construídos (Tabela 1) apresentavam concentrações de metais $\mathrm{Co}, \mathrm{Mn}$ e Ni compatíveis com rios de Classe 1 e de $\mathrm{Pb}$ e $\mathrm{Cu}$ com rios de Classe 3 (Tabela 2).

Embora as concentrações de metais alcalinos e alcalinos terrosos estivessem muito acima dos limites recomendados por Almeida (2010) para água de irrigação (Tabela 2), encontravam-se abaixo dos limites sugeridos por diferentes autores (Tabela 3) para água de reúso na irrigação, com exceção do $\mathrm{K}^{+}$. A Razão de Adsorção de Sódio (RAS) foi de $0,94 \mathrm{cmol} / \mathrm{L}$ (Tabela 1), portanto, encontrava-se abaixo do limite máximo para água de irrigação sugerido por Almeida (2010), que é de 1,5 cmol/L (Tabela 2), e um pouco acima da faixa recomendada por Feigin, Ravina e Shalhevet (1991) para água de reúso (Tabela 3 ). Isso pode ter comprometido a absorção dos nutrientes de forma equilibrada pelas plantas.

Os solos com adubação tradicional apresentaram capacidade de troca catiônica (CTC) elevada $\left(>10 \mathrm{cmol}_{\mathrm{c}} \cdot \mathrm{dm}^{-3}\right)$, enquanto os solos das unidades de reúso apresentavam CTC média $\left(>4,5 \mathrm{cmol}_{c} \cdot \mathrm{dm}^{-3}\right)$ (Tabela 5$)$. De acordo com Fageria e Stone (2004), a CTC ideal para o cultivo do feijoeiro é $7,9 \mathrm{cmol}_{\mathrm{c}} . \mathrm{dm}^{-3}$, logo, os solos das unidades de reúso apresentavam uma CTC abaixo da adequada para o cultivo dessa cultura e, mesmo assim, proporcionaram um estado nutricional melhor do que os solos que receberam a adubação tradicional. Isso possivelmente ocorreu devido ao teor de matéria orgânica (MO) presente no solo, que favorece a adsorção de grande quantidade de nutrientes catiônicos (PREZOTTI; GUARÇONI, 2013), pois os valores da $\mathrm{MO}$ em todas as unidades experimentais se encontram dentro da faixa média adequada, que

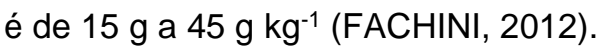

Os solos irrigados com água apresentaram melhores condições de reter e fornecer nutrientes para as plantas do que os solos irrigados com 
esgoto, uma vez que apresentaram maiores valores de soma das bases (SB) e de $\mathrm{MO}$ e, consequentemente, maiores valores de CTC. A $\mathrm{MO}$ influencia diretamente a CTC dos solos e atua como reservatório de $\mathrm{Ca}^{+2}, \mathrm{Mg}^{+2}$ e $\mathrm{K}^{+}$.

Comparando as concentrações presentes no efluente dos wetlands construídos (Tabela 1) utilizado para irrigar o feijão com aquela requerida para o seu bom desenvolvimento (Tabela 4), nota-se que as concentrações de $\mathrm{Mg}^{+2}$ e $\mathrm{Ca}^{+2}$ estão muito acima daquelas recomendadas para esta cultura, enquanto as de $\mathrm{K}^{+}, \mathrm{Mn}, \mathrm{Zn}$, Cu estão muito abaixo. Isso provocou deficiência nutricional na planta, conforme comprovado pelas análises químicas realizadas na parte aérea e nos grãos.

Tabela 1: Concentrações médias $\left(\mathrm{mg} \mathrm{L}^{-1}\right) \pm$ desvio padrão de metais nos efluentes das unidades wetlands construídos, utilizados para a irrigação do feijão

\begin{tabular}{|c|c|c|}
\hline & Parâmetro & Concentrações $\left(\mathrm{mg} \mathrm{L}^{-1}\right)$ \\
\hline \multirow{4}{*}{ Metais de transição } & Cobre (Cu) & $0,013 \pm 0,016$ \\
\hline & Manganês (Mn) & $0,012 \pm 0,004$ \\
\hline & Níquel (Ni) & $0,015 \pm 0,007$ \\
\hline & Cobalto (Co) & $0,008 \pm 0,003$ \\
\hline \multirow{2}{*}{ Metais pós-transição } & Chumbo (Pb) & $0,024 \pm 0,012$ \\
\hline & Zinco (Zn) & $0,023 \pm 0,023$ \\
\hline \multirow{2}{*}{ Metais alcalinos terrosos } & Cálcio (Ca) & $192,40 \pm 7,32$ \\
\hline & Magnésio (Mg) & $14,00 \pm 2,000$ \\
\hline \multirow{2}{*}{ Metais alcalinos } & Potássio (K) & $16,90 \pm 2,15$ \\
\hline & Sódio (Na) & $158,40 \pm 9,14$ \\
\hline \multicolumn{2}{|c|}{$\mathrm{pH}$} & $7,00 \pm 0,19$ \\
\hline \multicolumn{2}{|c|}{ RAS (cmolc/L) } & $0,94 \pm 0,05$ \\
\hline
\end{tabular}

Fonte: Elaboração própria.

Tabela 2: Concentrações máximas permissíveis para água de irrigação (mg. $\left.\mathrm{L}^{-1}\right)$

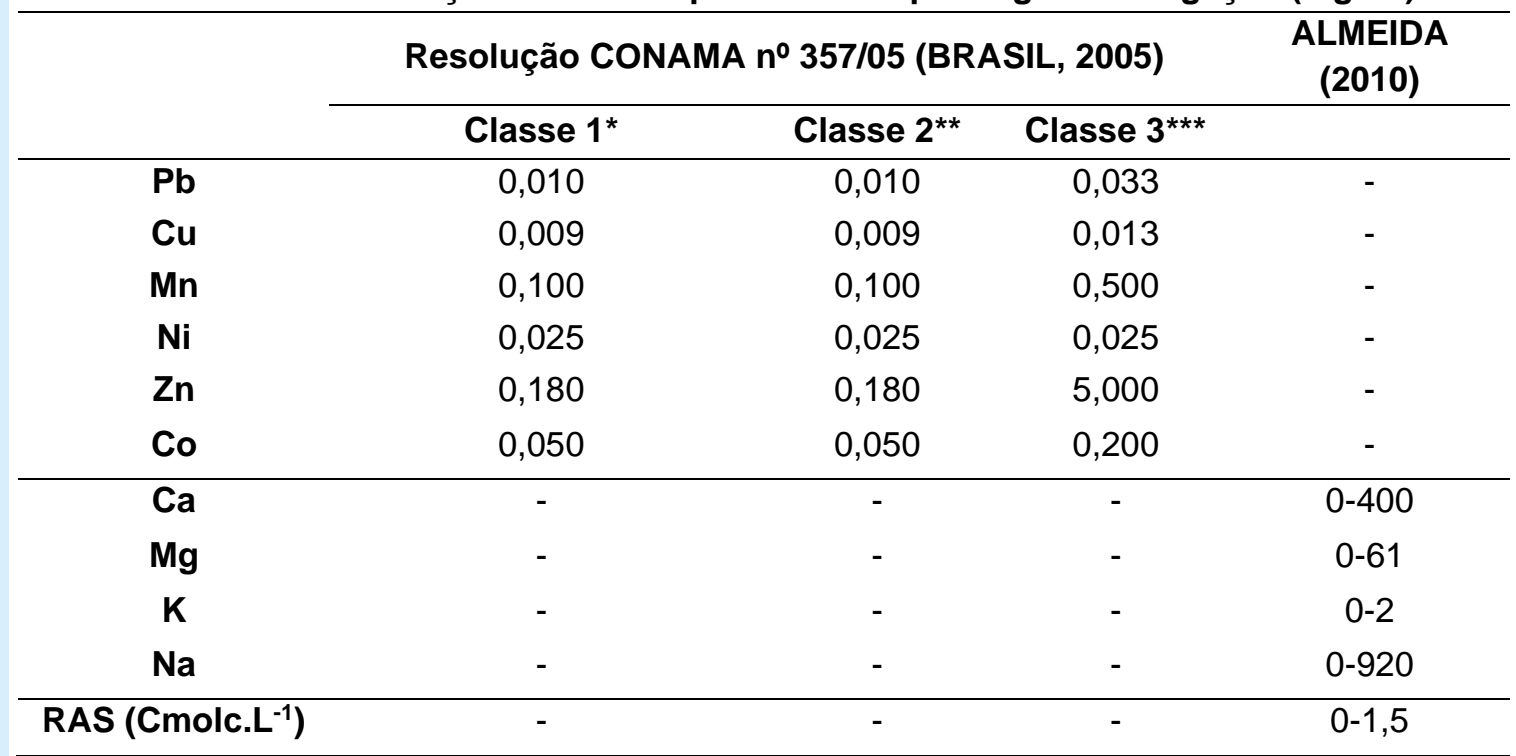

* irrigação de hortaliças que são consumidas cruas e de frutas que se desenvolvam rentes ao solo e que sejam ingeridas cruas sem remoção de película; ** irrigação de hortaliças, plantas frutíferas e de parques, jardins, campos de esporte e lazer, com os quais o público possa vir a ter contato direto; *** irrigação de culturas arbóreas, cerealíferas e forrageiras - não existem limites.

Fonte: Elaboração própria. 
Tabela 3: Limites recomendados para irrigação com esgoto tratado (água de reúso)

\begin{tabular}{|c|c|c|}
\hline Parâmetros & Limite & Referência \\
\hline $\mathrm{Pb}\left(\mathrm{mg} \cdot \mathrm{L}^{-1}\right)$ & 5,0 & FAO (1992); USEPA (2004) \\
\hline $\mathrm{Cu}\left(\mathrm{mg} \cdot \mathrm{L}^{-1}\right)$ & 0,2 & FAO (1992); USEPA (2004); FATTA et al. (2004) \\
\hline $\operatorname{Mn}\left(m g \cdot L^{-1}\right)$ & 0,2 & FAO (1992); USEPA (2004); FATTA et al. (2004) \\
\hline $\mathrm{Ni}\left(\mathrm{mg} \cdot \mathrm{L}^{-1}\right)$ & 0,2 & FAO (1992); USEPA (2004); FATTA et al. (2004) \\
\hline $\mathrm{Zn}\left(\mathrm{mg} \cdot \mathrm{L}^{-1}\right)$ & 2,0 & FAO (1992); USEPA (2004); FATTA et al. (2004) \\
\hline Co $\left(m g \cdot L^{-1}\right)$ & 0,05 & FAO (1992); USEPA (2004) \\
\hline $\mathrm{Ca}\left(\mathrm{mg} \cdot \mathrm{L}^{-1}\right)$ & 120 & FEIGIN; RAVINA; SHALHEVET (1991) \\
\hline$M g\left(m g \cdot L^{-1}\right)$ & 50 & FEIGIN; RAVINA; SHALHEVET (1991) e FATTA et al. (2004) \\
\hline $\mathrm{K}\left(\mathrm{mg} \cdot \mathrm{L}^{-1}\right)$ & 40 & FEIGIN; RAVINA; SHALHEVET (1991) \\
\hline $\mathrm{Na}\left(\mathrm{mg} \cdot \mathrm{L}^{-1}\right)$ & 200 & FATTA et al. (2004) \\
\hline RAS (Cmol.L-1) & $0,45-0,79$ & FEIGIN; RAVINA; SHALHEVET (1991) \\
\hline $\mathrm{pH}$ & $7,8-7,9$ & FEIGIN; RAVINA; SHALHEVET (1991) \\
\hline
\end{tabular}

Fonte: Elaboração própria.

Tabela 4. Concentrações de alguns micronutrientes $(\mathrm{Mn}, \mathrm{Zn}$ e $\mathrm{Cu})$ e macronutrientes ( $\mathrm{K}, \mathrm{Ca}$ e $\mathrm{Mg}$ ) requeridos pelo feijão (PERIN et al., 2005 )

\begin{tabular}{cc}
\hline Parâmetros & Níveis requeridos pelo feijão $\left(\mathbf{m g} \cdot \mathbf{L}^{-1}\right)$ \\
\hline $\mathbf{K}$ & $40-60$ \\
$\mathbf{C a}$ & $56-104$ \\
$\mathbf{M g}$ & 2,4 \\
$\mathbf{M n}$ & $2,5-20$ \\
$\mathbf{N a}$ & - \\
$\mathbf{Z n}$ & $4-20$ \\
$\mathbf{C u}$ & 0,6 \\
\hline
\end{tabular}

Fonte: Elaboração própria.

\section{Fertilidade dos solos}

Os solos irrigados com efluente apresentaram Percentual de Sódio Trocável (PST) superior àqueles irrigados com água. Os solos plantados com o cultivar BRS Estilo apresentaram maior potencial de sodificação do que os plantados com o cultivar Horizonte, mas nenhum deles se encontrava sódico, uma vez que o PST foi inferior a 15\% (RICHARDS, 1970).

Conforme a Tabela 5 , os valores obtidos para $\mathrm{Ca}^{+2}\left(>4 \mathrm{cmol}_{c} \cdot \mathrm{dm}^{-3}\right)$ e $\mathrm{Mg}^{+2}\left(>1 \mathrm{cmol}_{c} \cdot \mathrm{dm}^{-3}\right)$ com adubação tradicional ou com efluente doméstico se encontravam elevados (PREZOTTI; GUARÇONI, 2013), inclusive do nível adequado de $\mathrm{Ca}^{+2}$ para a cultura do feijão que é de 2,9cmolc. $\mathrm{dm}^{-3}$ (FAGERIA, 2001) e de $\mathrm{Mg}^{+2}$ de $1,2 \mathrm{cmol}_{\mathrm{c}} \mathrm{dm}^{-3}$ (FAGERIA; STONE, 2004). Os baixos valores do $\mathrm{K}^{+}$podem ser atribuídos à troca pelos cátions $\mathrm{Ca}^{+2}$ e $\mathrm{Mg}^{+2}$. Apenas os solos adubados tradicionalmente alcançaram o nível adequado de $\mathrm{K}^{+}$, que é de $0,2 \mathrm{cmol}_{\mathrm{c}} \cdot \mathrm{dm}^{-3}$ (FAGERIA, 2001). Os solos não apresentaram contaminação por alumínio, uma vez que a acidez potencial $\left(\mathrm{H}^{+}+\mathrm{Al}^{3+}\right)$ era menor do que $2,4 \mathrm{cmol} . \mathrm{dm}^{-3}$, que segundo Fageria e Stone (2004), é o valor adequado para o desenvolvimento do feijoeiro.

\section{Desenvolvimento da planta do feijão}

Segundo Aguiar et al. (2014), o ciclo do feijão é de 65 a 110 dias, porém, o ciclo do cultivar Estilo é de 85 a 95 dias, com floração média de 44 dias, enquanto o ciclo do cultivar Horizonte é de 85 dias, com floração média de 39 dias (CABRERA et al., 2019). Nesta pesquisa, a planta foi removida aos 20 dias após a floração e 
aos 60 dias após o plantio, a fim de analisar o seu estado nutricional. Caso completasse o ciclo, as folhas secariam e não haveria condições de realizar essas análises. Ainda assim, as plantas alcançaram alturas satisfatórias (Tabela 6).
$\mathrm{O}$ aumento do $\mathrm{pH}$ do solo, possivelmente, contribuiu para a redução da disponibilidade, solubilidade e mobilidade do chumbo $(\mathrm{Pb})$ nos solos (MELO et al., 2008).

Tabela 5: Fertilidade dos solos utilizados no cultivo do feijoeiro, avaliada no final do ciclo da cultura

\begin{tabular}{|c|c|c|c|c|c|}
\hline \multirow[t]{2}{*}{ Parâmetro } & \multirow[t]{2}{*}{ Unidade } & \multicolumn{2}{|c|}{ Irrigado com efluente } & \multicolumn{2}{|c|}{ Irrigado com água de poço* } \\
\hline & & Estilo & Horizonte & Ěstilo & Horizonte \\
\hline $\mathrm{pH}$ & & $7,47 \pm 0,76$ & $7,60 \pm 0,45$ & $8,20 \pm 0,20$ & $8,53 \pm 0,50$ \\
\hline$P$ & $\mathrm{mg} \cdot \mathrm{kg}^{-1}$ & $6,50 \pm 1,32$ & $3,900 \pm 0,21$ & $20,00 \pm 1,17$ & $20,00 \pm 1,00$ \\
\hline $\mathrm{K}^{+}$ & $\mathrm{cmol}_{\mathrm{c}} \cdot \mathrm{dm}^{-3}$ & $0,10 \pm 0,02$ & $0,07 \pm 0,01$ & $0,26 \pm 0,06$ & $0,19 \pm 0,02$ \\
\hline $\mathrm{Ca}^{+2}$ & $\mathrm{cmol}_{\mathrm{c} . \mathrm{dm}^{-3}}$ & $4,30 \pm 0,44$ & $3,25 \pm 0,22$ & $8,37 \pm 0,45$ & $8,40 \pm 1,14$ \\
\hline $\mathrm{Mg}^{+2}$ & $\mathrm{cmol}_{\mathrm{c} .} \cdot \mathrm{dm}^{-3}$ & $1,39 \pm 0,10$ & $1,00 \pm 0,06$ & $3,39 \pm 0,14$ & $3,40 \pm 0,36$ \\
\hline $\mathrm{Al}$ & $\mathrm{cmol}_{\mathrm{c} .} \cdot \mathrm{dm}^{-3}$ & $0,00 \pm 0,00$ & $0,00 \pm 0,00$ & $0,00 \pm 0,00$ & $0,00 \pm 0,00$ \\
\hline $\mathrm{Na}$ & $\mathrm{cmol}_{\mathrm{c}} \cdot \mathrm{dm}^{-3}$ & $0,39 \pm 0,11$ & $0,19 \pm 0,01$ & $0,27 \pm 0,01$ & $0,27 \pm 0,06$ \\
\hline $\mathrm{H}+\mathrm{Al}$ & $\mathrm{cmol}_{\mathrm{c}} \cdot \mathrm{dm}^{-3}$ & $0,00 \pm 0,00$ & $0,00 \pm 0,00$ & $0,00 \pm 0,00$ & $0,00 \pm 0,00$ \\
\hline $\mathrm{SB}$ & $\mathrm{cmol}_{\mathrm{c} .} \mathrm{dm}^{-3}$ & $6,18 \pm 0,56$ & $4,50 \pm 0,29$ & $12,31 \pm 0,10$ & $12,25 \pm 0,50$ \\
\hline СтС & $\mathrm{cmol}_{\mathrm{c}} \cdot \mathrm{dm}^{-3}$ & $6,55 \pm 0,89$ & $4,50 \pm 0,29$ & $12,31 \pm 0,06$ & $12,25 \pm 0,13$ \\
\hline MO & g. $\mathrm{kg}^{-1}$ & $19,66 \pm 2,51$ & $14,73 \pm 0,26$ & $39,01 \pm 0,15$ & $35,08 \pm 0,46$ \\
\hline RAS & Cmol.dm-3 & $0,23 \pm 0,06$ & $0,13 \pm 0,002$ & $0,11 \pm 0,003$ & $0,11 \pm 0,01$ \\
\hline PST & $\%$ & $5,89 \pm 1,04$ & $4,22 \pm 0,045$ & $2,17 \pm 0,056$ & $2,22 \pm 0,469$ \\
\hline
\end{tabular}

H + Al - Acidez potencial; SB - Soma das Bases; CTC - Capacidade de Troca Catiônica; MO Matéria orgânica. *Controle Fonte: Elaboração própria.

Figura 1: Planta do feijão em fase de produção e de enchimento das vagens

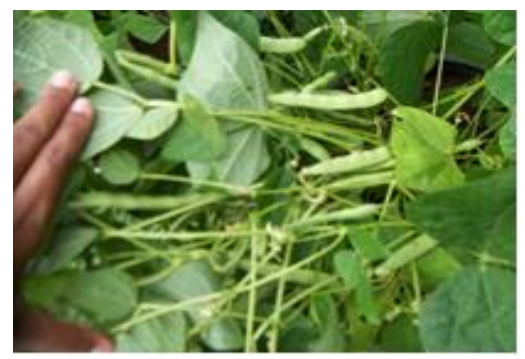

Fonte: Próprio autor.

Segundo Aguiar et al. (2014), o feijão atinge alturas entre 40 e $60 \mathrm{~cm}$, portanto, os cultivares BRS Estilo e BRS Horizonte, embora não tenham completado seu ciclo, atingiram alturas aceitáveis. As alturas do cultivar BRS Horizonte foram inferiores e as do cultivar BRS Estilo, superiores àquelas encontradas por Frandoloso et al. (2009), respectivamente, de $60 \mathrm{~cm}$ e $29 \mathrm{~cm}$.

O teste de Kruskall-Walis mostrou que não houve diferenças significativas $(p>0,05)$ entre as alturas médias das plantas dos dois cultivares de feijão (Estilo e Horizonte) quando irrigadas com água de reúso, e a altura média do Cultivar BRS Horizonte foi significativamente $(p<0,05)$ maior do que a do cultivar BRS Estilo quando irrigada com água de poço. Ao comparar as alturas médias das mesmas plantas nos dois diferentes modos de irrigação, percebe-se que o Cultivar BRS Estilo alcançou altura média significativamente superior $(p<0,05)$ àquela irrigada com água de poço (Tabela 6).

A quantidade de vagens produzida pelas 
plantas do cultivar BRS Estilo irrigadas com água de reúso foi um pouco maior, e do cultivar BRS Horizonte foi significativamente $(p<0,05)$ superior àquelas irrigadas com água de poço. Porém, nos dois sistemas de irrigação, o número de vagens por planta foi inferior a 11 (Tabela 7), conforme observado por Andrade et al. (2004), utilizando diferentes cultivares de feijão, adubadas com a mesma proporção de N:P:K no plantio direto. Isso possivelmente ocorreu em função da colheita antecipada da planta e do transplantio de 6 (seis) plantas para uma única cova, localizada no centro do vaso $\mathrm{com} 40 \mathrm{~cm}$ de diâmetro, pois o procedimento correto é de 2 a 3 sementes por cova (PÁDUA FELIPE, 2000).

O cultivar BRS Horizonte irrigado com efluente produziu uma quantidade de vagens por planta (vagens/planta) significativamente maior $(p<0,05)$ que o irrigado com água de poço, mas, para o cultivar BRS Estilo, não houve diferença significativa. O número de vagens por planta do cultivar BRS Horizonte, irrigado com água de reúso, foi significativamente superior $(p<0,05)$ àquelas irrigadas com água de poço e, para a BRS Estilo, não foi observada diferença significativa.

Tabela 6: Alturas médias $(\mathrm{cm}) \pm$ desvio padrão das plantas de feijão das espécies estilo e horizonte ao longo do seu ciclo

\begin{tabular}{|c|c|c|c|c|}
\hline \multirow{2}{*}{$\begin{array}{l}\text { Data da } \\
\text { medição }\end{array}$} & \multicolumn{2}{|c|}{ Irrigada com água de reúso } & \multicolumn{2}{|c|}{$\begin{array}{l}\text { Irrigada com água de poço } \\
\text { (controle) }\end{array}$} \\
\hline & Estilo & Horizonte & Estilo & Horizonte \\
\hline $24 / 07 / 2011$ & $43,67 \pm 3,21$ & $44,25 \pm 2,50$ & $35,10 \pm 3,76$ & $41,15 \pm 3,00$ \\
\hline $04 / 08 / 2011$ & $53,33 \pm 1,53$ & $53,25 \pm 2,50$ & $43,30 \pm 1,73$ & $53,32 \pm 2,65$ \\
\hline $14 / 08 / 2011$ & $56,33 \pm 2,08 \mathrm{aA}$ & $57,50 \pm 2,89 a A$ & $46,20 \pm 1,32 \mathrm{aB}$ & $54,20 \pm 2,00 \mathrm{bA}$ \\
\hline
\end{tabular}

Médias seguidas pelas mesmas letras minúsculas comparam as cultivares dentro do mesmo sistema de irrigação, e letras maiúsculas comparam as mesmas cultivares irrigadas com águas diferentes, pelo teste de Kruskall-Walis $(\mathrm{p}<0,05) .{ }^{*}$ Controle

Fonte: Elaboração própria.

Tabela 7: Número de vagens por planta e o total de vagens cultivares de feijão em cada unidade de reúso

\begin{tabular}{ccccccccc} 
& \multicolumn{3}{c}{ Irrigado com água de reúso } & \multicolumn{3}{c}{ Irrigado com água de poço* $^{*}$} \\
\cline { 2 - 9 } & \multicolumn{2}{c}{ BRS Estilo } & \multicolumn{2}{c}{ BRS Horizonte } & \multicolumn{2}{c}{ BRS Estilo } & \multicolumn{2}{c}{ BRS Horizonte } \\
\cline { 2 - 9 } & $\begin{array}{c}\text { Total } \\
\text { vagens }\end{array}$ & $\begin{array}{l}\text { Vagens/ } \\
\text { planta }\end{array}$ & $\begin{array}{c}\text { Total } \\
\text { vagens }\end{array}$ & $\begin{array}{c}\text { Vagens/ } \\
\text { planta }\end{array}$ & $\begin{array}{c}\text { Total } \\
\text { vagens }\end{array}$ & $\begin{array}{c}\text { Vagens/ } \\
\text { planta }\end{array}$ & $\begin{array}{c}\text { Total } \\
\text { vagens }\end{array}$ & $\begin{array}{c}\text { Vagens/ } \\
\text { planta }\end{array}$ \\
\hline Média & $45,67 \mathrm{aA}$ & $7,60 \mathrm{aA}$ & $46,00 \mathrm{aB}$ & $7,67 \mathrm{bB}$ & $43,00 \mathrm{aA}$ & $7,33 \mathrm{aA}$ & $31,33 \mathrm{aA}$ & $5,25 \mathrm{aA}$ \\
Despad & 1,53 & 0,26 & 1,00 & 0,58 & 1,00 & 0,21 & 7,77 & 1,31 \\
Mínimo & 44,00 & 7,30 & 45,00 & 7,00 & 42,00 & 7,00 & 25,00 & 4,20 \\
Máximo & 47,00 & 7,80 & 47,00 & 8,00 & 44,00 & 7,40 & 40,00 & 6,70 \\
\hline
\end{tabular}

Médias seguidas pelas mesmas letras minúsculas comparam as cultivares dentro do mesmo sistema de irrigação e letras maiúsculas, comparam as mesmas cultivares irrigadas com águas diferentes, pelo teste de Kruskall-Walis $(p<0,05) .{ }^{*}$ Controle

Fonte: Elaboração própria.

\section{Análise nutricional da planta e dos grãos do feijão}

As plantas irrigadas com água de reúso apresentaram teores de $\mathrm{Fe}, \mathrm{Zn}$ e $\mathrm{Mn}$ aceitáveis no tecido vegetal (Tabela 8). Embora os teores de $\mathrm{P}$ nos tecidos das plantas irrigadas com água de reúso tenham sido menores do que naquelas irrigadas com água de poço, tais teores encontravam-se dentro da faixa adequada nas folhas de feijão (Tabela 8). Foi observado por Silva Vahl e Peske (2003) teores de fósforo (P) nas folhas do feijoeiro (Phaseolus vulgaris L.) do cultivar BR-FEPAGRO 44 GUAPO BRILHANTE, 
plantado em solos sem e com adubação fosfatada no início do florescimento, respectivamente, de 3,25 e $5,74 \mathrm{~g} \cdot \mathrm{Kg}^{-1}$. Isso indica que quanto maior o teor de fósforo no solo, maior a quantidade de $\mathrm{P}$ nas folhas das plantas. A absorção de $\mathrm{P}$ nos tecidos vegetais das plantas irrigadas com água de poço foi maior em função das maiores quantidades desse elemento nos solos (Tabela 5).

Tabela 8: Teores médios \pm desvio padrão de macro e micronutrientes no tecido vegetal das plantas dos cultivares de feijão

\begin{tabular}{|c|c|c|c|c|c|}
\hline \multirow[b]{2}{*}{ Elemento } & \multicolumn{2}{|c|}{ BRS Estilo } & \multicolumn{2}{|c|}{ BRS Horizonte } & \multirow{2}{*}{$\begin{array}{c}\text { Valor } \\
\text { adequado para } \\
\text { a folha* }\end{array}$} \\
\hline & $\begin{array}{l}\text { Água de } \\
\text { reúso }\end{array}$ & $\begin{array}{l}\text { Água de } \\
\text { poço** }\end{array}$ & $\begin{array}{l}\text { Água de } \\
\text { reúso }\end{array}$ & $\begin{array}{l}\text { Água de } \\
\text { poço** }\end{array}$ & \\
\hline \multicolumn{6}{|c|}{ Macronutrientes $\left(\mathrm{g} \cdot \mathrm{kg}^{-1}\right)$} \\
\hline $\mathbf{P}$ & $2,96 \pm 0,41$ & $4,89 \pm 0,97$ & $2,52 \pm 0,38$ & $3,18 \pm 0,36$ & $2,5-4,0$ \\
\hline K & $6,44 \pm 4,50$ & $13,44 \pm 2,61$ & $4,24 \pm 0,92$ & $11,04 \pm 1,77$ & $20-25$ \\
\hline $\mathrm{Ca}$ & $30,37 \pm 3,85$ & $23,30 \pm 3,06$ & $30,17 \pm 2,26$ & $20,70 \pm 1,39$ & $10-25$ \\
\hline Mg & $8,60 \pm 2,61$ & $5,20 \pm 1,01$ & $10,87 \pm 0,93$ & $5,10 \pm 0,26$ & $2,5-5,0$ \\
\hline \multicolumn{6}{|c|}{ Micronutrientes $\left(\mathrm{mg} \cdot \mathrm{kg}^{-1}\right)$} \\
\hline $\mathrm{Cu}$ & $4,68 \pm 1,12$ & $9,86 \pm 2,49$ & $2,10 \pm 1,15$ & $1,44 \pm 0,32$ & $10-20$ \\
\hline $\mathrm{Fe}$ & $131,15 \pm 4,06$ & $100,76 \pm 1,43$ & $117,50 \pm 2,42$ & $106,10 \pm 2,82$ & $100-450$ \\
\hline Mn & $38,74 \pm 8,16$ & $23,91 \pm 5,43$ & $32,04 \pm 1,72$ & $29,17 \pm 3,10$ & $30-300$ \\
\hline $\mathrm{Zn}$ & $24,84 \pm 3,92$ & $16,61 \pm 1,55$ & $26,57 \pm 1,10$ & $15,94 \pm 2,74$ & $20-100$ \\
\hline
\end{tabular}

${ }^{*}$ Fonte: Malavolta et al. (1997). ${ }^{* *}$ Controle.

Fonte: Elaboração própria.

As folhas das plantas de feijão dos dois cultivares, independente do tipo de água de irrigação, apresentaram carência de potássio $(K)$ e cobre $(\mathrm{Cu})$. A deficiência de $\mathrm{K}^{+}$foi maior nas plantas irrigadas com água de reúso, cujos solos apresentavam teores de $\mathrm{Ca}^{+2}$ e $\mathrm{Mg}^{+2}$ muito elevados (Tabela 5). Isso, possivelmente, ocorreu porque 0 excesso de $\mathrm{Ca}^{+2}$ e de $\mathrm{Mg}^{+2}$ impede a absorção do $\mathrm{K}^{+}$(GOEDERT; COREY; SYERS, 1975; PAIVA; SAMPAIO; MARTINEZ, 1998). O cultivar BRS Horizonte apresentou carência maior de $\mathrm{Cu}$ do que o BRS Estilo, independente do tipo de água utilizada na irrigação, tendo uma maior absorção na planta irrigada com água de poço. 0 excesso de $\mathrm{Ca}^{+2}$, possivelmente, inibiu a absorção do Cu (SILVA; TREVIZAM, 2015).

As plantas irrigadas com água de reúso absorveram uma maior quantidade $\mathrm{Mn}$ e $\mathrm{Zn}$, atendendo as exigências nutricionais do feijão, enquanto naquelas irrigadas com água de poço, a absorção foi menor, o que causou uma pequena deficiência desses nutrientes. Isso, talvez, ocorreu em função dos solos apresentarem $\mathrm{pH}$ acima de 8,0 e elevada concentração de $P$ (Tabela 5). A deficiência do $\mathrm{Zn}$ é comum em solos neutros e alcalinos, como, também, naqueles que receberam uma adubação fosfatada elevada, devido à interação negativa entre P e Zn (SENGIK, 2003).
Os teores de $\mathrm{Ca}^{+2} \mathrm{e} \mathrm{Mg}^{+2}$ no tecido vegetal das plantas irrigadas com os dois tipos de água foram maiores do que os recomendados para a planta do feijão. As plantas irrigadas com água de reúso absorveram uma quantidade muito maior de $\mathrm{Mg}^{+2}$, enquanto aquelas irrigadas com água de poço (controle) captaram maior quantidade de $\mathrm{Ca}^{+2}$. Somente as plantas do cultivar BRS Estilo irrigadas com água de poço apresentaram teores de Fe abaixo da faixa recomendada (Tabela 8).

Nos grãos, os teores de $\mathrm{Fe}$ e $\mathrm{Zn}$ foram satisfatórios e maiores para as plantas irrigadas com água de reúso, mas os teores de $\mathrm{Mn}$ se encontravam abaixo dos limites adequados para a planta, independente do tipo de água de irrigação utilizada. Os teores de $\mathrm{Cu}$ nos grãos, assim como no tecido vegetal, foram inadequados, considerando os dois tipos de água de irrigação (poço e água de reúso) (Tabela 9).

Embora os teores de $\mathrm{K}^{+}$no tecido vegetal estivessem abaixo da faixa recomendada, os grãos apresentaram teores adequados, sendo maiores quando irrigados com água de reúso.

Os teores de $\mathrm{P}$ nos grãos e no tecido vegetal foram adequados, considerando os dois tipos de água de irrigação. A absorção dos nutrientes $\mathrm{P}$ e $\mathrm{K}^{+}$pelas plantas irrigadas com água de poço foi pouco superior àquelas irrigadas com água de reúso. 
Os teores de $\mathrm{Mg}^{+2}$ nos grãos de feijão, irrigados com os dois tipos de água, foram satisfatórios, enquanto os de $\mathrm{Ca}^{+2}$, insatisfatórios.

As concentrações de $\mathrm{P}, \mathrm{K}^{+}$e $\mathrm{Fe}$ nos grãos dos cultivares BRS Estilo e BRS Horizonte, irrigados com água de reúso e água de poço, estavam dentro dos limites recomendados para garantir um bom desenvolvimento e nutrição da cultura do feijão, e as de $\mathrm{Mn}$ e $\mathrm{Cu}$, abaixo. Os grãos de todas as plantas apresentaram deficiência de $\mathrm{Ca}^{+2}$ (Tabela 9).

Os valores de $\mathrm{pH}$ dos solos (Tabela 5) eram superiores ao adequado $(6,0$ a 6,5$)$ para um bom desenvolvimento da cultura do feijão (PREZOTTI; GUARÇONI, 2013). Isso, possivelmente, dificultou a absorção equilibrada dos nutrientes pelas plantas, uma vez que 0 aumento do $\mathrm{pH}$ afeta os micronutrientes $\mathrm{Cu}, \mathrm{Fe}, \mathrm{Mn}$ e $\mathrm{Zn}$, na solução do solo (ABREU; LOPES; SANTOS, 2007). Os valores elevados do $\mathrm{pH}$ dos solos podem ter favorecido as perdas de $\mathrm{N}$ por volatilização de NH3 (PREZOTTI; GUARÇONI,
2013). Em função da baixa disponibilidade de $\mathrm{Cu}$, $\mathrm{Mn}$ e $\mathrm{Zn}$ na solução do solo, os teores nos tecidos vegetais (Tabela 8) e nos grãos (Tabela 9) encontravam-se abaixo dos limites exigidos para um bom estado nutricional das plantas do feijão. Contudo, os valores de $\mathrm{pH}$ dos solos acima de 7,0 (Tabela 5) favoreceram a retenção de cátions em função do aumento da CTC e, mesmo estando acima de 7,5, evitou a toxidez por Al, pois a solubilidade desse elemento aumenta em pH abaixo de 5,5 e acima de 7,5 (MIGUEL et al., 2010).

O cultivar BRS Estilo irrigado com água de reúso apresentou melhores teores de nutrientes quando comparados com o BRS Horizonte, e, mesmo com algumas deficiências nutricionais, o feijão Estilo adaptou-se melhor às condições da água de reúso. Portanto, o cultivar de feijão BRS Estilo respondeu melhor à aplicação do esgoto tratado pelas wetlands construídos do que o BRS Horizonte.

Tabela 9: Concentração média \pm desvio padrão de macro e micronutrientes nos grãos dos cultivares de feijão Estilo e Horizonte

\begin{tabular}{|c|c|c|c|c|c|c|}
\hline \multirow[b]{2}{*}{ Nutriente } & \multicolumn{2}{|c|}{ Estilo } & \multicolumn{2}{|c|}{ Horizonte } & \multirow{2}{*}{$\begin{array}{l}\text { Limite } \\
\text { adequado }\end{array}$} & \multirow[b]{2}{*}{ Referência } \\
\hline & $\begin{array}{l}\text { Água de } \\
\text { reúso }\end{array}$ & $\begin{array}{l}\text { Água de } \\
\text { poço* }^{*}\end{array}$ & $\begin{array}{l}\text { Água de } \\
\text { reúso }\end{array}$ & $\begin{array}{c}\text { Água de } \\
\text { poço* }^{*}\end{array}$ & & \\
\hline \multicolumn{7}{|c|}{ Macronutrientes $\left(\mathrm{g} \cdot \mathrm{kg}^{1}\right)$} \\
\hline$P$ & $5,48 \pm 0,59$ & $4,62 \pm 0,35$ & $4,84 \pm 0,28$ & $4,28 \pm 0,16$ & 2,6 a 6 & 1 \\
\hline K & $15,24 \pm 0,49$ & $12,77 \pm 0,61$ & $14,04 \pm 0,24$ & $12,64 \pm 0,35$ & 9,2 a 22 & 1 \\
\hline $\mathrm{Ca}$ & $1,30 \pm 0,10$ & $1,30 \pm 0,31$ & $1,20 \pm 0,10$ & $1,10 \pm 0,20$ & $\begin{array}{c}2,20 \text { a } 2,8 \\
1,5 \text { a } 5,5\end{array}$ & $\begin{array}{l}1 \\
2\end{array}$ \\
\hline$M g$ & $1,80 \pm 0,10$ & $1,73 \pm 0,06$ & $1,8 \pm 0,06$ & $1,63 \pm 0,06$ & 1,8 a 4,0 & 1 \\
\hline
\end{tabular}

\begin{tabular}{lrrrrrr}
\hline \multicolumn{7}{c}{ Micronutrientes $\left(\mathbf{m g}^{-k^{-1}}\right)$} \\
$\mathrm{Cu}$ & $1,44 \pm 0,01$ & $1,39 \pm 0,09$ & $1,44 \pm 0,01$ & $1,39 \pm 0,09$ & 3 a 80 & 3 \\
$\mathrm{Fe}$ & $43,16 \pm 4,95$ & $35,14 \pm 0,99$ & $46,49 \pm 1,05$ & $26,63 \pm 2,84$ & 25 a 80 & 4 \\
$\mathrm{Mn}$ & $10,51 \pm 0,68$ & $10,99 \pm 0,83$ & $10,51 \pm 0,66$ & $10,03 \pm 0,83$ & 15 a 18 & 5 \\
$\mathrm{Zn}$ & $33,66 \pm 2,06$ & $23,03 \pm 1,00$ & $32,31 \pm 1,63$ & $29,28 \pm 1,78$ & 32 a 65 & 1
\end{tabular}

1 - Oliveira e Thung (1988); 2 - Jost, (2008); 3 - Pais e Benton (1997); 4 - Kabata-Pendias e Pendias (1992) e 5 Kabata-Pendias e Pendias (2001). ${ }^{*}$ Controle.

Fonte: Elaboração própria.

\section{CONCLUSÃO}

As unidades experimentais wetland construídos produziram efluentes com concentrações de metais compatíveis com aqueles recomendados para a irrigação de culturas, seja com água de poço ou água de reúso. Contudo, as concentrações de $\mathrm{Ca}^{+2}$ e $\mathrm{Mg}^{+2}$ encontravam-se acima e as de $\mathrm{K}^{+}, \mathrm{Mn}, \mathrm{Zn}$, e $\mathrm{Cu}$, abaixo dos limites recomendados para a água de irrigação do feijão. Porém, isso não interferiu no desempenho e estado nutricional das plantas e 
dos grãos, uma vez que os resultados obtidos foram semelhantes nos dois sistemas, o adubado tradicionalmente e irrigado com água de poço (controle) e aquele sem adubação e irrigado com água de reúso (esgoto tratado).

A utilização da água de reúso se mostrou adequada, uma vez que a alocação dos macro e micronutrientes para o tecido vegetal das plantas irrigadas com esse tipo de água foi maior para todos os nutrientes, com exceção do $\mathrm{P}$ e $\mathrm{K}^{+}$. Os grãos produzidos pelas plantas irrigadas com água de reúso também apresentaram melhor estado nutricional.

O cultivar BRS Estilo adaptou-se melhor às condições da água de reúso quando comparado ao BRS Horizonte. Portanto, o cultivar de feijão BRS Estilo respondeu melhor à aplicação do esgoto tratado pelas wetlands construídos do que o BRS Horizonte.

\section{AGRADECIMENTO}

À Fundação de Amparo às Pesquisas do Estado da Bahia - FAPESB pelo financiamento da pesquisa.

\section{REFERÊNCIAS}

ABREU, C. A.; LOPES, A. S.; SANTOS, G. C. G. XI Micronutrientes. In: NOVAIS, R. F.; ALVAREZ V., V. H.; BARROS, N. F.; FONTES, R. L. F.; CANTARUTTI, R. B.; NEVES, J. C. L. (Ed.). Fertilidade do solo. ViçosaMG: Sociedade Brasileira de Ciência do Solo, 2007. p. 645-736 .

AGUIAR, A. T. E.; GONÇALVES, C.; PATERNIANI, M. E. A. G. Z.; TUCCI, M. L. S.; CASTRO, C. E. F. Instruções agrícolas para as principais culturas econômicas. Instituto Agronômico, (Boletim IAC, n.ำ 200), 7.ㄹ Ed. rev. e atual. Campinas, 2014. 452 p.

ALMEIDA, O. A. Qualidade da água de irrigação. Cruz das Almas: Embrapa Mandioca e Fruticultura, 2010. 234 p.

ANDRADE, C. A. B.; PATRONI, S. M. S.; CLEMENTE, E.; SCAPIM, C. A. Produtividade e qualidade nutricional de cultivares de feijão em diferentes adubações. Ciência e Agrotecnologia, v. 28, n. 5, p. 1077-1086, set./out. 2004.

APHA-AWWA-WPCF. Standard Methods for the Examination of Water and Wastewater. 16th edition, American Public Health Association, Washington, DC, 1985.1268p.

BRASIL. Resolução CONAMA no 357, de 17 de março de 2005. Dispõe sobre a classificação dos corpos de água e diretrizes ambientais para 0 seu enquadramento, bem como estabelece as condições e padrões de lançamento de efluentes, e dá outras providências. Diário Oficial da República Federativa do Brasil de 18 de março de 2005. Seção 1, páginas 58-63. Poder Executivo, Brasília, DF, 2005.

CABRERA, J. L. D.; WENDLAND, A.; FARIA, L. C.; Costa, J. G. C.; Peloso, M. J. D.; Pereira, H. S.; MELO, L. C. Árvore do conhecimento - Feijão. AGEITEC Agência Embrapa de Informação. Disponível em: http://www.agencia.cnptia.embrapa.br/gestor/feijao/arvo re/CONTAG01 106 243200313236.html . Acesso em: 18 mar. 2019.

EMBRAPA - Empresa Brasileira de Pesquisa Agropecuária. Ministério da Agricultura, Pecuária e Abastecimento. Manual de análises químicas de solos plantas e fertilizantes. Embrapa Solos. Embrapa Informática Agropecuária. Ministério da Agricultura, Pecuária e Abastecimento. Editor técnico: Fábio Cesar da Silva. 2. ed. revisada e ampliada. Brasília, DF, 2009. 627 p.

FACHINI, L. Frações e estoques de carbono orgânico em solo do planalto catarinense cultivado com pinus. 2012. 49p. Dissertação (Mestrado) Programa de Pós-Graduação em Manejo do Solo, Centro de Ciências Agroveterinárias, Universidade do Estado de Santa Catarina, Lages, 2012, 49p.

FAGERIA, N. K. ; STONE, L. F. Produtividade de feijão no sistema plantio direto com aplicação de calcário e zinco. Pesquisa Agropecuária Brasileira, Brasília, v.39, n.1, p.73-78, jan. 2004.

Resposta de arroz de terras altas, feijão, milho e soja à saturação por base em solo de cerrado. Revista Brasileira de Engenharia Agrícola e Ambiental, v. 5, p. 416-424, set/dez. 2001.

FATTA, D.; SALEM, Z.; MOUNTADAR, M.; ASSOBHEI, O.; LOIZIDOU, M. Urban wastewater treatment and reclamation for agricultural irrigation: The situation in Morocco and Palestine. The Environmentalist, v. 24, n. 4, p. 227-236, dez. 2004.

FEIGIN, A.; RAVINA, I.; SHALHEVET, J. Irrigation with treated sewage effluent. Management for environmental protection. Berlin: Springler, 1991. 224 p.

FOOD AND AGRICULTURE ORGANIZATION - FAO. Wastewater treatment and use in agriculture. FAO Irrigation and Drainage, Paper 47. By M.B. Pescod, Rome, 1992, $169 \mathrm{p}$.

FRANDOLOSO, G; TRAGNAGO, J. L; NETO, N. Ensaio de valor de cultivo e uso de feijoeiro. In: SEMINÁRIO INTERINSTITUCIONAL DE ENSINO, PESQUISA E EXTENSÃO, XIII MOSTRA DE INICIAÇÃO CIENTÍFICA E VIII MOSTRA DE EXTENSÃO, 15., 2009, Cruz Alta. Anais... Cruz AltaRS: Gráfica UNICRUZ, 2009. CD ROM.

GOEDERT, W. J.; COREY, R. B.; SYERS, J. K. The effects on potassium equilibria in soils of Rio Grande do Sul, Brazil. Soil Science, v.120, p.107-111, 1975. 
JOST, E. Genética dos teores de cálcio e de ferro em grão de feijão comum. 2008, 42p. Dissertação (Mestrado) - Centro de Ciências Rurais, Universidade Federal de Santa Maria, Santa Maria, 2008.

MALAVOLTA, E.; VITTI, G. C.; OLIVEIRA, S. A. Avaliação do estado nutricional das plantas: princípios e aplicações. 2 ed. Piracicaba: POTAFOS, 1997. $319 \mathrm{p}$.

MELO, E. E. C.; NASCIMENTO, C. W. A.; SANTOS, A. C. Q.; SILVA, A. S. Disponibilidade e fracionamento de $\mathrm{Cd}, \mathrm{Pb}, \mathrm{Cu}$ e $\mathrm{Zn}$ em função do $\mathrm{pH}$ e tempo de incubação com o solo. Ciência e Agrotecnologia, Lavras, v. 32, n. 3, p. 776-784, maio/jun. 2008.

MIGUEL, P. S. B.; GOMES, F. T.; ROCHA, W. S. D.; MARTINS, C. E.; CARVALHO, C. A.; OLIVEIRA, A. V. Efeitos tóxicos do alumínio no crescimento das plantas: mecanismos de tolerância, sintomas, efeitos fisiológicos, bioquímicos e controles genéticos. Juiz de Fora-MG. CES Revista, Juiz de Fora, v. 24, p. 11-30, 2010.

MOSCOSO, J. C.; LEON, G. S. Curso de Tratamiento y Uso de Aguas Residuales. Lima-Peru: OPS/CEPIS/PUB96, 1996. $151 \mathrm{p}$.

PÁDUA FELIPE, M. A Cultura do feijão. Informação Tecnológica. EMATER-MG - Empresa de Assistência Técnica e Extensão Rural do Estado de Minas Gerais, maio, 2000, 16p.

PAIVA, E. A. S.; SAMPAIO, R. A.; MARTINEZ, H. E. P. Composition and quality of tomato fruit cultivated in nutrient solutions containing different calcium concentrations. Journal of Plant Nutrition, Philadelphia, v. 21, p. 2653-2661, 1998.

PERIN, K; CASSINI, S. T. ; GONÇALVES, R. F. ; KELLER, R. Reuso de efluente de lagoa de polimento em cultivos agrícolas. In: CONGRESSO BRASILEIRO DE ENGENHARIA SANITÁRIA E AMBIENTAL, 23., 2005, Campo Grande. Anais... Rio de Janeiro-TJ: ABES, 2005. p 1-6.

PREZOTTI, L. C.; GUARÇONI, M. A. Guia de interpretação de análise de solo e foliar. Vitória-ES: Instituto Capixaba de Pesquisa - Incaper, AssistênciaTécnica e Extensão Rural, 2013. 104 p.

RAN, N.; AGAMI, M.; ORON, G. A pilot study of constructed wetlands using duckweed (LemnagibbaL.) for treatment of domestic primary effluent in Israel. Water Research, v. 38, n. 9, p. 2241-2248, mai. 2004.

RICHARDS, L. A. Diagnóstico y reabilitación de Suelos salinos y sodicos. Departamento de
Agricultura dos Estados Unidos da América, Manual de Agricultura Núm. 60, 1970. 172 p.

RODRIGUES, L. N. Níveis de reposição da evapotranspiração da mamoneira irrigada com água residuária. 2008. 161p. Tese (Doutorado) - Centro de Tecnologia e Recursos Naturais, Universidade Federal de Campina Grande, Campina Grande, 2008.

SALOMONS W.; FORSTNER U.; MADER P. Heavy metals: problems and solutions. Verlag: Springer, 1995. $412 \mathrm{p}$.

SENGIK, E. S. Os macronutrientes e os micronutrientes das plantas. Versão 2003. OLIVEIRA, J, P; THUNG, M, D,T. Nutrição Mineral, 2003. In: ZINMERMANN, M. J. O; ROCHA, M.; YAMADA,T. (Ed) Cultura do feijoeiro: fatores que afetam a produtividade. Piracicaba: Associação Brasileira para pesquisa de potassa e do fosfato,1988. p.175-212.

SILVA, R. J. S.; VAHL, L. C.; PESKE, S. T. Rendimento de grãos no feijoeiro em função dos teores de fósforo nas sementes. Revista Brasileira de Agrociência, v. 9, n. 3, p. 247-250, jul.-set. 2003.

SILVA, M. L. S.; TREVIZAM, A. R. Interações iônicas e seus efeitos na nutrição das plantas. Informações agronômicas, n. 149, p. 10-16, mar. 2015.

SILVA, S. C.; RAMOS, M. L. G.; BERNARDES, R. S. Remoção de sais em wetlands construídos no tratamento de esgotos domésticos primário. Revista Eletrônica de Gestão e Tecnologias Ambientais, v. 6, n. 1, p. 125-138, abr. 2018.

BERNARDES, R. S.; RAMOS, M. L. G. Remoção de matéria orgânica do esgoto em solo de wetland construído. Revista Engenharia Sanitária e Ambiental, v. 20, n. 4, p. 533-542, out./dez. 2015.

SANTANA, A. M. F. C. Remoção de traços de metais de esgotos domésticos em sistemas wetlands construídos com meio suporte de solo local. In: CONGRESSO INTERAMERICANO DE ENGENHARIA SANITÁRIA E AMBIENTAL - AIDIS, 33., 2012, Salvador. Anais... Salvador-Ba: ABES, 2012.

UNITED STATES ENVIRONMENTAL PROTECTION AGENCY - USEPA 2004. Guidelines for water reuse. EPA/625/R-04/108, Washington, DC, 2004, 480 p.

VON SPERLING, M.; SEZERINO, P. H.

Dimensionamento de wetlands construídos no Brasil.

Boletim Wetlands Brasil, Edição Especial, dezembro, 2018. 65 p. ISSN 2359- 0548. 